\title{
Wheat streak mosaic virus in Australia: Relationship to Isolates from the Pacific Northwest of the USA and Its Dispersion Via Seed Transmission
}

\author{
Geoffrey I. Dwyer, Agricultural Research Western Australia, Locked Bag No. 4, Bentley Delivery Centre, Perth, WA \\ 6983, Australia; Mark J. Gibbs, School of Botany and Zoology, Australian National University, Canberra, ACT \\ 2000, Australia; Adrian J. Gibbs, 7 Hutt St., Yarralumla, Canberra, ACT 2600, Australia; and Roger A. C. Jones, \\ Agricultural Research Western Australia, Locked Bag No. 4, Bentley Delivery Centre, Perth, WA 6983, Australia, \\ and State Agricultural Biotechnology Centre, Murdoch University, Perth, WA 6150, Australia
}

\begin{abstract}
Dwyer, G. I., Gibbs, M. J., Gibbs, A. J., and Jones, R. A. C. 2007. Wheat streak mosaic virus in Australia: Relationship to isolates from the Pacific Northwest of the USA and its dispersion via seed transmission. Plant Dis. 91:164-170.

Wheat streak mosaic virus (WSMV) was found for the first time in Australia in 2002. It subsequently was found widely dispersed around the continent and was shown to be seedborne in wheat. The coat protein $(\mathrm{CP})$ gene sequences of nine WSMV isolates from eastern and southwestern Australia are reported, one obtained directly from infected wheat seed, three from seedlings grown from infected wheat seed, and five from infected wheat plant samples. These sequences were compared with those of $66 \mathrm{WSMV} \mathrm{CP}$ sequences, including eight previously sequenced Australian isolates. All 17 Australian sequences formed a closely knit monophyletic cluster as part of the D1 subclade of WSMV previously only reported from the Pacific Northwest of the United States. The close phylogenetic relationships of these sequences indicate that the Australian outbreak arose from a single incursion, the source of which appears to be the Pacific Northwest. Three Australian CP sequences were identical, one from the location of the post-entry quarantine facility at Tamworth, New South Wales, and two from seed that had originally been propagated at that facility. These three sequences were closest to the Pacific Northwest sequences and differed from them by as little as eight nucleotides $(0.76 \%)$. The sequence of a third seedborne isolate originally from the same source differed from the other two seedborne isolates by two nucleotides, indicating that the immigrant WSMV population may have been variable. The other Australian sequences differed from the three identical ones by only one to four nucleotides. The phylogenetic pattern and small number of nucleotide differences between individual isolates from different geographic locations fit the scenario that the virus was introduced once in seed of wheat breeding material, multiplied where it was introduced, and then was dispersed over long distances around the Australian continent along standard distribution routes for wheat breeding lines, germ plasm, and crop seed. These conclusions provide a cautionary tale indicating the importance of effective monitoring of imported plant materials for exotic virus diseases during post-entry quarantine.
\end{abstract}

Additional keywords: biosecurity, introduction, mite vector, phylogeography

Wheat streak mosaic virus (WSMV) is a member of the genus Tritimovirus in the family Potyviridae, the largest group of plant viruses. It is a significant pathogen of wheat and other cereals in the Americas, Europe, Asia, and North Africa (3). It is an especially serious pathogen in the Great Plains region of North America $(5,11)$. WSMV is transmitted from infected to healthy wheat plants by the wheat leaf curl mite (Aceria tosichella) (10), which also

Corresponding author: R. A. C. Jones

E-mail: rjones@agric.wa.gov.au

The nine new WSMV sequences reported in this paper are in the GenBank database under Accession Codes DQ462276-70 and DQ888801-05.

Accepted for publication 5 September 2006.

DOI: 10.1094/PDIS-91-2-0164

(C) 2007 The American Phytopathological Society occurs in Australia (16). WSMV was first definitively found in Australia in 2002, in wheat plants in a cereal breeding facility in the Australian Capital Territory $(6,8)$, and was identified by reverse transcriptionpolymerase chain reaction (RT-PCR) using WSMV-specific primers (9) and by genome sequencing. In 2003, it was also found at several other eastern Australian wheat breeding sites and in wheat crops and grasses in the states of New South Wales, Queensland, South Australia, and Victoria (7,8). Between 2003 and summer 2006, it was not detected in the state of Western Australia despite intensive targeted surveillance that involved testing $>35,000$ samples from likely sites. During further large-scale surveillance in which 5,873 samples were tested by the Western Australian Department of Agriculture and Food in autumn 2006, WSMV was eventually found in volunteer wheat at nine sites in the state. In winter 2006, the first infec- tion in commercial wheat crops was found in the state. It has not yet been reported in the island state of Tasmania or the Northern Territory.

Although WSMV was shown to be transmitted via seed to progeny plants of maize more than 30 years ago (17), there was no convincing evidence of seed transmission in wheat until recently, when WSMV was shown unequivocally to be transmitted to a small but consistent proportion of seedlings grown from WSMVinfected wheat plants (21). The WSMVinfected seed was found in a collection of wheat breeding lines originally imported to Australia in early 2003 from the International Maize and Wheat Improvement Center (CIMMYT) in Mexico. The lines had been propagated once in post-entry quarantine in Tamworth, New South Wales, and then in 2004 in an irrigated wheat breeding nursery at Toowoomba in southern Queensland, which was already known to be WSMV contaminated (1). In late 2004, seed from the CIMMYT collection was sent to Perth, Western Australia, where it was grown in a post-entry quarantine glasshouse. Some of the seedlings showed mosaic symptoms, and WSMV was detected by serology, RT-PCR, and genome sequencing (21). Seed transmission of WSMV in wheat was confirmed subsequently in three different Australian laboratories, two of which used seed from the same CIMMYT collection, while the third laboratory used seed from WSMVinfected wheat crops from New South Wales $(20,22)$.

WSMV caused little obvious crop loss in Australia in 2003 to 2004, except in a few severely damaged crops of irrigated wheat in the Murrumbidgee Irrigation area of New South Wales (Fig. 1A and B). However, this situation changed dramatically in 2005 when it severely damaged early-sown "graze-and-grain" wheat crops growing throughout the high rainfall zone of the New South Wales grainbelt, causing crop failure in over 5,000 hectares (20). Wheat crops in the Murrumbidgee Irrigation area were also severely affected. In 2006 , the area of crop failure expanded to 20,000 hectares despite a growing season that was not conducive to WSMV epidemics. The future WSMV-induced economic loss was estimated at \$AUD 21 million by 
the New South Wales Department of Primary Industry on the assumption that most farmers in the affected region of the state would decide to stop growing "graze-andgrain" wheat in future years and grow lower value "graze-and-grain" cereal crops, such as oats and triticale.

In this paper, we report the sequences of the complete coat protein $(\mathrm{CP})$ genes of an additional nine Australian isolates of WSMV from infected wheat plants or seed. These, together with eight other Australian WSMV sequences already deposited in GenBank, were analyzed to establish how they are related phylogenetically to each other and to the worldwide population of WSMV, which was previously shown to consist of four main clusters (24), and whether they shed any light on the source, time of arrival, and movement of WSMV around the Australian continent.

\section{MATERIALS AND METHODS}

Seed source and virus isolates. The nine WSMV isolates sequenced came from widely dispersed locations around Australia (Fig. 1A, Table 1). Three isolates were from WSMV-infected seedlings from the original infected CIMMYT wheat nursery collection (SP-1, SP-5, and SP-6) (21). The Galong isolate was obtained directly from wheat seed supplied by Paul Parker (New South Wales Department of Primary Industries, Young) from an infected 2005 wheat crop at Galong, New South Wales. A field isolate collected in 2003 at Ginninderra, Australian Capital Territory (ACT), was kindly supplied by Mark Ellis (CSIRO Division of Plant Industry, Canberra). Four isolates collected in 2006 from infected volunteer wheat plants in the Mt. Burdett, Yerritup, Gibson, and Kondinin districts of southwestern Australia were supplied by Brenda Coutts (Agricultural Research Western Australia, South Perth).

RNA extraction and RT-PCR. Virus RNA extraction, RT-PCR, and sequencing reactions were done in duplicate for each isolate. Infected wheat leaf material was ground to a fine powder in liquid nitrogen, and total RNA was extracted with an RNeasy Plant Mini kit (Qiagen, Doncaster, Victoria, Australia) using procedures suggested by the manufacturer. The entire WSMV CP gene was amplified by RT-PCR using two pairs of primers that generate overlapping products. Primers WSMV-CP1 (5'-CGGACGGATTTAGGAGAAGAG forward primer) and WSMV-CP3 (5'ATGCAGTGGTAGACCCATC - reverse primer) amplify a 634-bp fragment from the $5^{\prime}$ end of the CP gene. Primers WSMV-CP2 (5'-AAGGGCTTGACGTGACAGAGG forward primer) and WSMV-CP4 (5'CGCTCAAATCCTGGTACTC - reverse primer) amplify a 581-bp region from the 3 '-end of the CP gene. RT-PCR was done using the GeneAmp RNA PCR kit (Applied Biosystems, Scoresby, Australia) as suggested by the manufacturer. The RT reaction mixture had a final volume of 10 $\mu \mathrm{l}$ and contained 10 pmol reverse primer (WSMV-CP3 or WSMV-CP4) and $1 \mu \mathrm{l}$ of
RNA extract. The reaction was incubated at $42^{\circ} \mathrm{C}$ for $30 \mathrm{~min}$, followed by $96^{\circ} \mathrm{C}$ for 5 $\min$. For PCR, the volume of the reaction mixture was increased to $50 \mu \mathrm{l}$, and 10
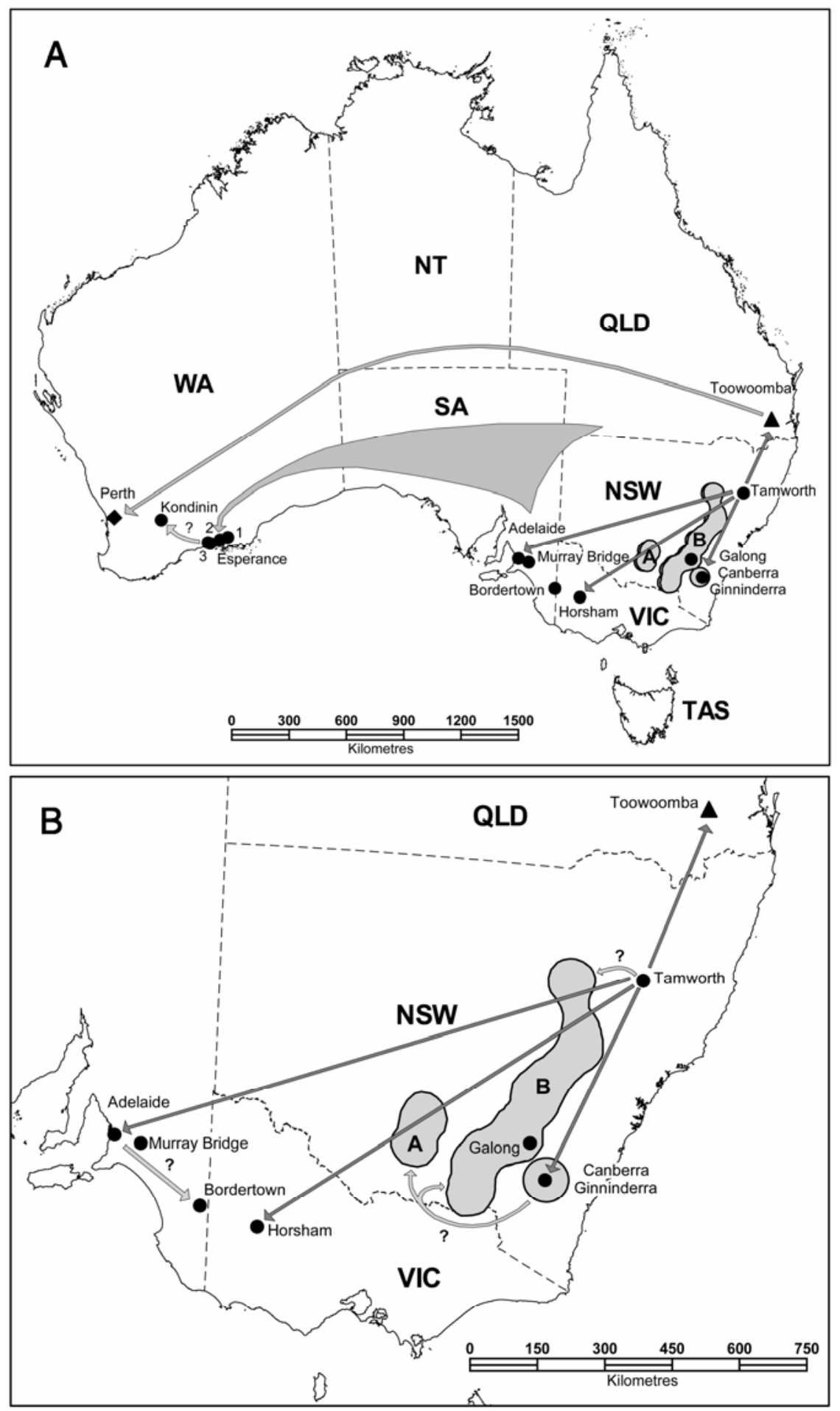

Fig. 1. Maps of the Australian continent (A) and southeast Australia (B) showing the locations from which the 17 sequenced Wheat streak mosaic virus (WSMV) isolates were obtained, and the probable virus distribution routes in infected wheat seed. Disks $(\bullet)$ show locations where isolates were found; triangle $(\boldsymbol{\Delta})$ shows the source of the three seedborne isolates detected in post-entry quarantine; and diamond $(\bullet$ shows where seed-infected isolates were identified under post-entry quarantine. Bold arrows indicate probable distribution routes from the incursion site to the primary breeding centers. Shaded arrows indicate suspected onward distribution routes. States: NSW $=$ New South Wales; NT = Northern Territory; QLD = Queensland; SA = South Australia; VIC = Victoria; WA = Western Australia. Areas of NSW affected by major WSMV epidemics in 2005: A, Murrumbidgee irrigation area; B, "slopes" region. For details of individual isolates see Table 1; Esperance locations 1, 2, and 3 are where isolates Mt. Burdett, Yerritup, and Gibson originated, respectively. 
pmol forward primer (SB103 or SB104) was added. PCR cycling involved initial denaturation at $94^{\circ} \mathrm{C}$ for $3 \mathrm{~min}$, followed by 30 cycles of $94^{\circ} \mathrm{C}$ for $30 \mathrm{~s}, 55^{\circ} \mathrm{C}$ for 30 $\mathrm{s}$, and $72^{\circ} \mathrm{C}$ for $60 \mathrm{~s}$, with a final time for extension at $72^{\circ} \mathrm{C}$ for $7 \mathrm{~min}$. PCR products were purified using Qiagen PCR Purification kit (Qiagen, Doncaster, Victoria, Australia) following the manufacturer's instructions. quenced directly from both strands in an ABI 3730 DNA Analyzer using BigDye v. 3.1 Terminator chemistry (Applied Biosystems). Raw sequence data were edited with SeqEd v.1.0.3 (Applied Biosystems) and the overlapping fragments concatenated using BioEdit v. 5.0.6. (14), and submitted to the GenBank database.

Sequences and their analysis. The SP$1 \mathrm{CP}$ gene sequence was from an isolate that had already been partially sequenced (21). The GenBank Accession Codes for the eight new WSMV isolates are given in Table 1. Sequences of 66 WSMV isolates were obtained from GenBank, and included the CP gene sequences of the eight Australian isolates (see Table 1) from diverse locations in eastern Australia from the initial report of the Australian outbreak (7; R. Mago, M. H. Ellis, G. J. Rebetzke, and $\mathrm{P}$. Chu, unpublished work).

Nucleotide sequences were aligned using CLUSTALX (19) with default parameters, and the reading frames of the few gaps required for alignment were checked by eye. Neighbor-joining (NJ) trees (23) were obtained using the algorithm in CLUSTALX, and the phylogeny of the sequences also was investigated heuristically by maximum parsimony (MP) and maximum likelihood (ML) methods using reconnection (TBR) method $(25,26)$. The ML tree was found using a general time-
Sequencing. RT-PCR products were sePAUP version $4.0 \mathrm{~b} 10$ and the tree branch

reversible model $(\mathrm{GTR}+\mathrm{G}+\mathrm{I})$, allowing rate variation among sites, with a gamma distribution for four rate categories, allowing invariant sites, and with no molecular clock. The amount of synonymous or nonsynonymous variation in the aligned sequences was identified using the DnDscan program (13).

Sequence comparisons showed that the $\mathrm{CP}$ sequence of the El Batan 3 isolate from Mexico (4) was so distinct from those of all the WSMV isolates that it dominated tree comparisons, so it was omitted from the main phylogenetic analyses.

\section{RESULTS}

Sequence analysis. The 1,047-nt CP gene of all 17 Australian WSMV isolates had nucleotide sequences that were almost identical, differing from one another by none to eight nucleotides $(\leq 0.764 \%$ nucleotide differences, mean pairwise difference $0.298 \% \pm 0.158 \%$ ). Two seedborne isolates, SP-1 and SP-5, and the Tamworth 1 isolate were identical. The other Australian sequences differed by no more than four nucleotides from these three identical sequences. Most of the differences between sequences involved a single sequence that differed from all the others. The three identical sequences and those of Adelaide 1, Adelaide 2, Ginninderra, and Kondinin all encoded the same CP amino acid sequence, as all their nucleotide differences were synonymous. The other Australian sequences encoded no more than six amino acid differences overall.

Phylogenetic analysis of all 75 available WSMV CP sequences using three different methods gave similar results. All placed the Australian isolates in a single cluster (Fig. 2) within WSMV Clade D, as defined by Stenger et al. (24). All methods placed the Mt. Burdett and Gibson sequences with the Tamworth 2 sequence, while the Yerri-

Table 1. Origins and sources of the 17 Australian Wheat streak mosaic virus isolates used

\begin{tabular}{llll}
\hline Isolate & Origin & Source & Accession no. $^{\mathbf{b}^{\circ}}$ \\
\hline SP-1 & CIMMYT - 1ISWSN5 & Seed & DQ462278.2 \\
SP-5 & CIMMYT - 21SAWSN85 & Seed & DQ462276.1 \\
SP-6 & CIMMYT - 20SAWSN88c & Seed & DQ462277.1 \\
Ginninderra & Ginninderra, ACT & Field & DQ462279.1 \\
Mt Burdett & Mt. Burdett, WA & Field & DQ888801.1 \\
Yerritup & Yerritup, WA & Field & DQ888802.1 \\
Gibson & Gibson, WA & Field & DQ888803.1 \\
Kondinin & Kondinin, WA & Field & DQ888805.1 \\
Galong & Galong, NSW & Seed & DQ888804.1 \\
Canberra & Black Mountain, ACT & Glasshouse & AY327865.2 \\
Tamworth 1 & Tamworth, NSW & Field & AY327866.2 \\
Tamworth 2 & Tamworth, NSW & Field & AY327867.1 \\
Adelaide 1 & Waite Institute, SA & Field & AY327868.3 \\
Adelaide 2 & Waite Institute, SA & Field & AY327869.2 \\
Bordertown & Bordertown, SA & Field & AY327870.1 \\
Murray Bridge & Murray Bridge, SA & Field & AY327872.2 \\
Horsham & Horsham, VIC & Field & AY327871.2 \\
\hline
\end{tabular}

a The first nine isolates are from this study. The second eight isolates are from Ellis et al. (8) and from R. Mago, M. H. Ellis, G. J. Rebetzke, and P. Chu (GenBank; unpublished work). ACT = Australian Capital Territory; NSW = New South Wales; SA = South Australia; WA = Western Australia; VIC = Victoria.

${ }^{\mathrm{b}}$ Decimal value indicates number of sequences corrections in GenBank.

c From Toowoomba, Queensland. tup and Galong sequences formed another subcluster. These two subclusters fell into a single unresolved polytomy with the other 12 Australian sequences. The Kondinin and Ginninderra sequences were basal to other Australian sequences in the $\mathrm{NJ}$ tree (Fig. 2) but not the likelihood and parsimony trees. However, this was shown to be an artifact of the NJ algorithm by directly comparing the sequences (see below and Table 2).

Stenger et al. (24) used NJ trees and a bootstrap analysis to identify the four main WSMV clades. We used the ML, MP, and NJ methods and found the same four main clusters (clades A to D) with the same membership in all our best phylogenetic trees. Significant support for the four main clusters was also found in a parsimony bootstrap analysis, confirming the original clade assignments. Clade D previously consisted of 54 closely related isolates from the United States, one from Canada, and two from Turkey. Within this clade, four subclades were inferred by Stenger et al., who used bootstrapped NJ analysis. These subclades were completely congruent with the groupings we found, and this was supported by all three methods of phylogenetic analysis. However, the different methods inferred slightly different arrangements of minor groupings (Fig. 2).

All our analyses placed the Australian sequences as a single cluster, most probably monophyletic, within the subclade D1 cluster, which previously only contained three isolates from the Pacific Northwest of the United States. The sequences of these three U.S. isolates, from Washington State, Idaho, and Montana, differed from one another by 11, 17, and 20 nucleotides. They also differed from the closest Australian sequence by a minimum of 8,9 , and 17 nucleotides, respectively (Table 2). The three identical Australian sequences (Tamworth 1, SP-1, and SP-5) were closest to those from the Pacific Northwest isolates, and in particular to that of the Washington State isolate.

Codon variability of the WSMV CP gene. The non-synonymous to synonymous ratios (Dn/Ds) found in the $\mathrm{CP}$ sequence data for the nine new Australian WSMV isolates resembled those for the sequences previously reported in the United States (24). However, the Dn/Ds ratios for the sequences reported by Mago et al. (GenBank, unpublished) differed. DnDscan analyses (13) showed that most of the nucleotide differences between the original 54 Clade D sequences were synonymous, and pairwise comparisons of these sequences gave a mean Dn/Ds score ratio of 0.39 . This is similar to the pairwise score ratio of 0.28 given by the 75 Clade $\mathrm{B}, \mathrm{C}$, and D sequences, and is typical of many other sets of closely related viral gene sequences. The nine new WSMV sequences reported here also had more synonymous than non-synonymous differences (Dn/Ds score ratio 0.67), and six of 


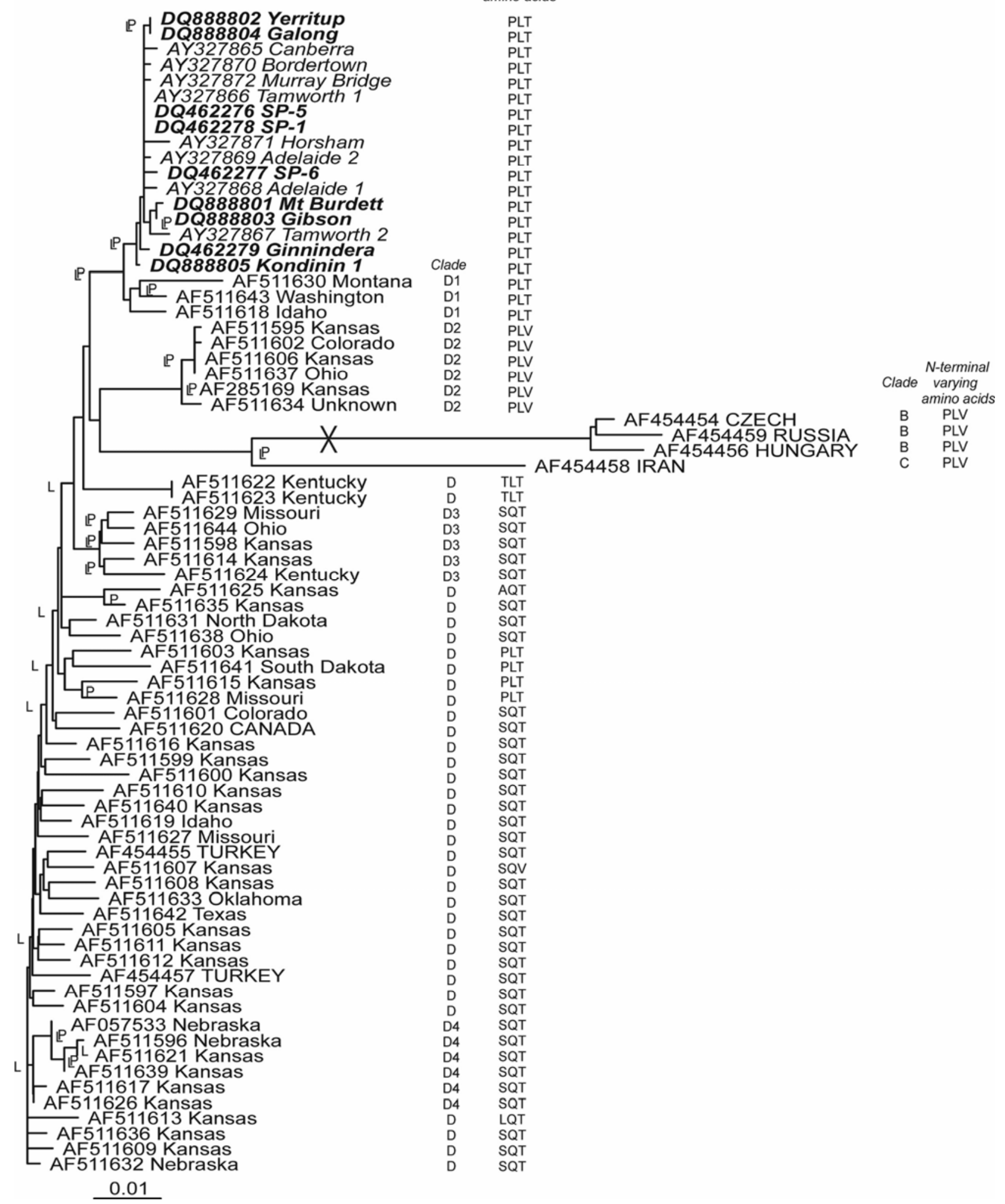

Fig. 2. A dendrogram illustrating a neighbor-joining (NJ) tree calculated from the coat protein $(\mathrm{CP})$ sequences of 58 clade $\mathrm{B}, \mathrm{C}$, and $\mathrm{D}$ isolates and the 17 Australian Wheat streak mosaic virus (WSMV) isolates. Relationships of $71 \mathrm{CP}$ sequences, excluding clade B and C sequences, were also inferred by maximum parsimony (MP) and maximum likelihood (ML), and nodes in the NJ tree supported by these methods are indicated in the tree by symbols P or L or both. The MP tree was a strict consensus of 11,046 equally most parsimonious trees found after 137,045,466 rearrangements were searched, and the ML tree was the best found during 92,924 rearrangements. Each CP gene sequence is identified by its GenBank accession code and the locality from which it was obtained, except for the seedborne isolates SP-1, SP-5, and SP-6. Australian isolates are in italics, with those first reported in this paper in bold. The GenBank Reference Sequence for WSMV (NC_001886) is an in silico pseudonym of AF057533 Nebraska, and the expression vector pWSMV-S1RN (AF329446) was derived from the same isolate but has three extra nucleotides between the P1 and HC-Pro genes. The figure shows the clade (24) to which the sequence is assigned, and also the amino acids encoded by its three $5^{\prime}$-terminal unusually variable codons. ' $\mathrm{X}$ ' marks the position of the root of the dendrogram, where it connects to the CP sequence of the Clade A El Batan 3 isolate and thence to those of other tritimoviruses. 
the eight differences between the Washington State and Tamworth 1, SP-1, and SP-5 sequences were also synonymous. However, the GenBank sequences reported by Mago et al. had more non-synonymous than synonymous differences ( $\mathrm{Dn} / \mathrm{Ds}$ score ratio 1.50 ), mostly because the four differences between the Tamworth 2 sequence and other Australian sequences were all non-synonymous, as were half of the four differences in the Horsham sequence.

The synonymous and non-synonymous variability of individual codons was not randomly distributed. An analysis made using DnDscan showed much of the variation was confined to a small subset of codons; a scan of the Clade D sequences gave almost the same pattern of variation as a scan of the combined Clade C and D sequences. Table 3 lists the 17 codon positions with more than $12 \%$ pairwise differences among the codons at each position. Only three of those codon positions varied non-synonymously, and all were in the $5^{\prime}$ terminal part of the $\mathrm{CP}$ gene; $98 \%$ of the differences in codon 21 (nucleotide 61) were non-synonymous, as were all the differences in codon 30 (nucleotide 89), and $87 \%$ of those of codon 92 (nucleotides 274/5). The other 14 varying codons mostly varied synonymously, and most of the codon positions that varied synonymously differed by transitions, except for two, codons 149 and 157, that differed by transversions. The Australian sequences differed from one another at 23 different

Table 2. Numbers of coat protein (CP) nucleotide differences between the Wheat streak mosaic virus (WSMV) isolates within subclade $\mathrm{D} 1^{\mathrm{a}}$

\begin{tabular}{lccccc}
\hline $\begin{array}{l}\text { WSMV } \\
\text { isolate }\end{array}$ & $\begin{array}{c}\text { Accession } \\
\text { no. }\end{array}$ & $\begin{array}{c}\text { Washington } \\
\text { State }\end{array}$ & Idaho & Montana & $\begin{array}{c}\text { Tamworth 1, } \\
\text { SP-5, and SP-1 }\end{array}$ \\
\hline Washington State & AF511643 & 0 & 11 & 17 & - \\
Idaho & AF511618 & 11 & 0 & 20 & - \\
Montana & AF511630 & 17 & 20 & 0 & - \\
Tamworth 1 & AY327866 & 8 & 9 & 17 & 0 \\
SP-5 & DQ462276 & 8 & 9 & 17 & 0 \\
SP-1 & DQ462278 & 8 & 9 & 17 & 0 \\
Bordertown & AY327870 & 9 & 10 & 18 & 1 \\
Murray Bridge & AY327872 & 9 & 10 & 18 & 1 \\
Adelaide 2 & AY327869 & 9 & 10 & 18 & 1 \\
Kondinin & DQ888805 & 9 & 10 & 18 & 1 \\
Yerritup & DQ888802 & 9 & 10 & 18 & 1 \\
Galong & DQ888804 & 9 & 10 & 18 & 1 \\
Canberra & AY327865 & 10 & 11 & 19 & 2 \\
Adelaide 1 & AY327868 & 10 & 11 & 19 & 2 \\
Ginninderra & DQ462279 & 10 & 11 & 19 & 2 \\
SP-6 & DQ462277 & 10 & 11 & 19 & 2 \\
Gibson & DQ888803 & 10 & 11 & 19 & 2 \\
Mt. Burdett & DQ888801 & 11 & 12 & 20 & 3 \\
Tamworth 2 & AY327867 & 12 & 13 & 21 & 4 \\
Horsham & AY327871 & 12 & 13 & 19 & 4 \\
\hline
\end{tabular}

a The number of nucleotide differences between the each of the Australian WSMV CP sequences $(1,047 \mathrm{nt})$ and those of three isolates from the Pacific Northwest of the United States; and also between the three identical Australian sequences most closely similar to the Pacific Northwest isolates and the other Australian sequences.

nucleotide positions, but only one of these, position 768 , was among the unusually variable sites in the Clade $\mathrm{C}$ and $\mathrm{D}$ sequences. Although the average pairwise difference between the Clade C and D sequences was only $2.91 \%, 98$ of the 350 codons of the $\mathrm{CP}$ sequences did not vary at all. However, some had pairwise differences of up to $20.2 \%$ (maximum pairwise synonymous codon difference $18.2 \%$, nonsynonymous codon difference $18.6 \%$ ).

Notably, the amino acids encoded by the three non-synonymously varying sites (codons 21, 30, and 92) did not vary independently. In 36 of the 75 sequences, the three sites had amino acids $\mathrm{S}, \mathrm{Q}$, and $\mathrm{T}$; in 24 sequences they were $\mathrm{P}, \mathrm{L}$, and $\mathrm{T}$; and in 10 sequences they were $\mathrm{P}, \mathrm{L}$, and $\mathrm{V}$. Two isolates had $\mathrm{T}, \mathrm{L}$, and $\mathrm{T}$, while one each had: S, Q, and V; A, Q, and T; or L, Q, and $\mathrm{T}$. The distribution of these combinations was mostly congruent with the relationships of the sequences (Fig. 2). Subclade D2 CPs shared amino acids P, L, and V with those of clade B and C; the Australian isolates and subclade D1 CPs shared amino acids $\mathrm{P}, \mathrm{L}$, and $\mathrm{T}$; the Kentucky isolates had T, L, and T; and with minor exceptions all the others had amino acids $\mathrm{S}, \mathrm{Q}$, and $\mathrm{T}$. The more distantly related Clade A El Batan 3 isolate of WSMV from Mexico (Clade A) had the amino acids S, $\mathrm{S}$, and $\mathrm{D}$ in these $\mathrm{N}$-terminal varying positions.

\section{DISCUSSION}

Our phylogenetic analyses unequivocally placed the $\mathrm{CP}$ sequences of the 17 Australian isolates all within a single small cluster that grouped with the sequences of three isolates from the Pacific Northwest of the United States (the D1 subclade) to form a larger cluster. The closest North American and Australian sequences differed by only eight nucleotides. The simplest conclusion that can be drawn from

Table 3. Codons found by DnDscan analysis to have most of the non-synonymous changes in the coat protein (CP) gene of 75 Wheat streak mosaic virus isolates $^{\mathrm{a}}$

\begin{tabular}{|c|c|c|c|c|c|c|c|}
\hline $\begin{array}{l}\text { Codon position } \\
\text { (nucleotide } \\
\text { in CP gene) }\end{array}$ & $\begin{array}{l}\text { Codon position } \\
\text { (amino acid } \\
\text { in CP gene) }\end{array}$ & $\begin{array}{l}\text { Predominant } \\
\text { type of change }\end{array}$ & $\begin{array}{c}\text { Total } \\
\text { mean \% } \\
\text { difference }\end{array}$ & $\begin{array}{l}\text { Mean } \\
\% \text { TSs }\end{array}$ & $\begin{array}{l}\text { Mean } \\
\text { \% TVs }\end{array}$ & $\begin{array}{c}\text { Encoded } \\
\text { amino acid }\end{array}$ & $\begin{array}{c}\text { Position } \\
\text { in codon } \\
\text { that varies }\end{array}$ \\
\hline 33 & 11 & S & 13.13 & 13.13 & 0 & A & 3 \\
\hline 61 & 21 & NS & 18.78 & 16.08 & 2.7 & $\mathrm{~T} / \mathrm{S} / \mathrm{P} / \mathrm{A}$ & 1 \\
\hline 89 & 30 & NS & 16.58 & 0 & 16.58 & $\mathrm{~L} / \mathrm{Q}$ & 2 \\
\hline 120 & 40 & $\mathrm{~S}$ & 17.62 & 17.62 & 0 & $\mathrm{~S}$ & 3 \\
\hline $274 / 5$ & 92 & NS & 20.2 & 17.5 & 2.7 & $\mathrm{~V} / \mathrm{T}$ & 1 and 2 \\
\hline 339 & 113 & S(NS1) & 13.33 & 12.4 & 0.93 & $\mathrm{~V}(\mathrm{~A})$ & 3 \\
\hline 405 & 135 & $\mathrm{~S}$ & 16.69 & 16.69 & 0 & $\mathrm{~K}$ & 3 \\
\hline 447 & 149 & $\mathrm{~S}$ & 15.23 & 4.64 & 10.59 & A & 3 \\
\hline 471 & 157 & $\mathrm{~S}$ & 17.28 & 0.43 & 16.85 & A & 3 \\
\hline 633 & 211 & $S$ & 16.43 & 16.43 & 0 & $\mathrm{~N}$ & 3 \\
\hline 672 & 224 & $S$ & 14.7 & 14.7 & 0 & $\mathrm{~K}$ & 3 \\
\hline 681 & 227 & S & 13.58 & 11.75 & 1.83 & $\mathrm{P}$ & 3 \\
\hline 723 & 241 & $\mathrm{~S}$ & 18.19 & 15.49 & 2.7 & $\mathrm{R}$ & 3 \\
\hline 735 & 245 & S(NS2) & 14.04 & 12.21 & 1.83 & $\mathrm{E}(\mathrm{D})$ & 3 \\
\hline 768 & 256 & $S$ & 16.85 & 16.85 & 0 & $\mathrm{R}$ & 3 \\
\hline 909 & 303 & $S$ & 13.97 & 13.97 & 0 & V & 3 \\
\hline 930 & 310 & $\mathrm{~S}$ & 12.68 & 12.68 & 0 & Q & 3 \\
\hline
\end{tabular}

a $\mathrm{S}=$ synonymous change, $\mathrm{NS}=$ non-synonymous change, $\mathrm{TSs}=$ transition, $\mathrm{TV} s=$ transversion. 
this consistent phylogenetic pattern is that there was only a single Australian incursion, the source of which was apparently the Pacific Northwest United States. Extensive surveillance for WSMV in Western Australia in 2003 to 2006 failed to detect the virus until autumn 2006 despite its ready detection in eastern Australia since 2003. Although the phylogenetic analyses did not provide evidence for any particular pattern of dispersion within the Australian island continent, the small numbers of nucleotide differences between individual Australian isolates from different locations is consistent with the known distribution routes of wheat breeding material and crop seed (Fig. 1).

Significantly, the Australian WSMV sequences closest to those from the Pacific Northwest were the identical sequences for Tamworth 1 and the two seedborne isolates, SP-1 and SP-5. Although detected in a state post-entry quarantine glasshouse at Perth, Western Australia, the SP-1 and SP5 isolates were from newly introduced CIMMYT breeding lines known to have been propagated previously, once at Tamworth and a second time at Toowoomba, before the infected seed was sent to Perth (21). This pattern of distribution in infected seed lots is consistent with the suggestion that: (i) the Australian incursion started at the principal wheat post-entry quarantine facility at Tamworth; (ii) WSMV infection was initiated, an epidemic developed, and harvested seed became infected; and (iii) infection was subsequently dispersed around the Australian continent in seed of wheat breeding lines distributed from Tamworth to wheat breeding programs in different states. This scenario is consistent with the practice of Australian wheat breeding programs whereby newly imported breeding lines of wheat are propagated first for 1 year in quarantine at Tamworth before the seed harvested is distributed to primary wheat breeding centers such as those at Adelaide, Canberra, Horsham, and Toowoomba; WSMV was found at all these centers in 2003 (Fig. 1A). After further propagation at these primary breeding sites, the wheat breeding lines are distributed as seed to secondary and tertiary field trial sites for evaluation, and seed of newly selected wheat cultivars propagated with them is sent on to farms for multiplication. Dispersal of infected seed lots through such a seed distribution network could account for the presence of WSMV at all the sites where it has been found in eastern Australia, as well as the post-entry quarantine facility in Perth, and the sites at Esperance and Kondinin in southwestern Australia (Fig. 1A and B). The very large distances involved in dispersion to Western Australia (3,000 to $4,000 \mathrm{~km})$, which include the extensive deserts that constitute a significant natural barrier to movement of pests and pathogens, are illustrated in Figure 1A.
Dispersion into commercial wheat crops via WSMV-infected seed stocks could also explain its widespread distribution by 2005 in the New South Wales grainbelt (Fig. 1B). These conclusions about the incursion of WSMV into the Australian island continent and its subsequent dispersion over very large distances provide a cautionary tale indicating the importance of effective monitoring of imported plant materials for exotic virus diseases during post-entry quarantine, and the need to grow out the first generation within secure, quarantine glasshouses.

The number of differences between individual Australian sequences and their likely U.S. progenitors (Table 2) broadly agree with the seed distribution scenario outlined above, but there are some significant anomalies. Firstly, the sequences of the Tamworth 1, SP-1, and SP-5 isolates differ from those of other Australian isolates by up to four nucleotides (Table 2). Secondly, the Tamworth 2 and Horsham sequences, the two most different, are anomalous as, unlike other D1 subclade sequences, all the differences between Tamworth 2 and the other Australian sequences are non-synonymous, as are half of those in the Horsham sequence. Thirdly, the direct relationship of the Horsham sequence to those from the Pacific Northwest is atypical (Table 2). Although the sequences of Mago et al. in GenBank were re-edited to correct sequencing errors and the entries updated to reflect these changes (see Table 1), we suspect that errors still remain in the Horsham and Tamworth 2 isolates. Thus, three nucleotide differences may be the maximum number that emerged in the virus population while WSMV was spreading around Australia. However, the fact that the SP-6 sequence differs from Tamworth 1, SP-1, and SP-5 common sequence by two nucleotides indicates that the original immigrant source may have itself been diverse, and that "selection and stochastic processes such as genetic drift and population growth factors" may have produced the observed three nucleotide population difference (15). Thus, divergence from a diverse source population, rather than post-entry mutation, may be responsible for twothirds of the diversity of the Australian WSMV sequences. For similar reasons, we do not know whether the eight nucleotide differences between the Australian and North American isolates were acquired at source, en route, or after entering Australia, as we do not know whether the Australian population came directly from the Washington State isolate or from another part of the Pacific Northwest population that has not yet been sequenced.

When this paper was written, there was no firm evidence that WSMV was present in Australia before it was first detected in the Australian Capital Territory in 2002 $(6,8)$. As mentioned in the introduction, in
2003 it was found in four eastern Australian states. However, in Western Australia, it was not detected between 2003 and summer 2006 despite extensive, targeted surveillance and testing, only being found in the autumn of 2006. Given the extensive annual movement of breeding material and commercial cultivars of wheat around the continent as seed and the apparent delay in its appearance on the western side of the continent, it is likely that WSMV entered Australia within the last 10 to 20 years. Claims of its presence in South Australia in the 1980s and 1990s based on records of wheat plants with possible mosaic symptoms were never confirmed by serology, RT-PCR, or other tests (but see note added in proof). Roy French and colleagues $(4,12,24)$ have comprehensively studied the factors affecting the rate of increase of diversity of natural and experimental WSMV populations, and have derived an estimate of the long-term average rate of sequence change of the North American WSMV population. Unfortunately, the time of arrival of WSMV in Australia cannot be extrapolated by combining their results with our estimate of the diversity of the Australian population because the number of differences is too small and hence stochastic errors are likely to be large, the origin of those differences is problematic (see above), and the apparent rate of accumulation of differences may be quite different in recently emerged and established populations (18).

Our DnDscan analysis supports the finding by Stenger et al. (24) that most of the non-synonymous changes in the WSMV $\mathrm{CP}$ are confined to its variable $\mathrm{N}$-terminal region. This region is analogous to the variable $\mathrm{N}$-terminal region of the CPs of aphid-transmitted potyviruses (27), which is external to the virion and carries the "DAG" amino acid motif that is required for their aphid-transmission (2). This motif is absent in all published sequences of WSMV except for the El Batan 3 isolate. Our analysis has further shown that the non-synonymous variation is mostly confined to three nonadjacent codons in the 100-codon $\mathrm{N}$-terminus, and that three sets of three amino acids- $\mathrm{S}, \mathrm{Q}$, and $\mathrm{T} ; \mathrm{P}, \mathrm{L}$, and $\mathrm{V}$; and $\mathrm{P}, \mathrm{L}$, and $\mathrm{T}$ - are favored, suggesting that there may be selection for these combinations. These three combinations indicate that the length/size of the side chain of the amino acids, rather than their charge or polarity, may be the feature under selection, as in different WSMV CPs, codon 21 encodes amino acids A, L, $\mathrm{P}, \mathrm{S}$, or $\mathrm{T}$, all of which have small side chains. Codon 30 encodes L or Q, which have side chains of three carbons, and codon 92 encodes $\mathrm{T}$ or $\mathrm{V}$, which have side chains of two carbons. Similar amino acids are not found in the CP of Ryegrass mosaic virus (genus Rymovirus, family Potyviridae), which, like WSMV, is transmitted by eryiophyid mites. 
NOTE ADDED IN PROOF: WSMV was recently detected in a seed sample of South Australian wheat cv. Spear stored since 1997. We confirmed its detection by ELISA, RT$\mathrm{PCR}$, and sequencing.

\section{ACKNOWLEDGMENTS}

In addition to those who supplied WSMV isolates, we thank Cuiping Wang and Hui Phing Loo for technical assistance, and Brenda Coutts, Nichole Burges, Paul Chu, Paul Parker, and Gordon Murray for helpful advice and information.

\section{LITERATURE CITED}

1. Anonymous. 2003. Wheat virus detected at Leslie Research Centre. Pest Outbreak Alert. Queensland Department of Primary Industries, Toowoomba, Queensland, Australia.

2. Baulcombe, D. C., Lloyd, J., Manoussopoulos, I. N., Roberts, I. M., and Harrison, B. D. 1993. Signal for potyvirus-dependent aphid transmission of potato aucuba mosaic virus and the effect of its transfer to potato virus X. J. Gen.Virol. 74:1245-1253.

3. Brunt, A. A., Crabtree, K., Dallwitz, M., Gibbs, A., and Watson, L. 1996. Viruses of Plants: C.A.B. International, UK.

4. Choi, I. R., Hall, J. S., Henry, M., Zhang, L., Hein, G. L., French, R., and Stenger, D. C. 2001. Contributions of genetic drift and negative selection on the evolution of three strains of wheat streak mosaic tritimovirus. Arch. Virol. 146:619-628.

5. Christian, M. L., and Willis, W. G. 1993. Survival of wheat streak mosaic virus in grass hosts in Kansas from wheat harvest to fall wheat emergence. Plant Dis. 77:239-242.

6. Ellis, M. H., Rebetzke, G. J., and Chu, P. 2003. First report of Wheat streak mosaic virus in Australia. Plant Pathol. 52:808.

7. Ellis, M. H., Rebetzke, G. J., Kelman, W. M., Moore, C. S., and Hyles, J. E. 2004. Detection of Wheat streak mosaic virus in four pasture grass species in Australia. Plant Pathol. 53:239.
8. Ellis, M. H., Rebetzke, G. J., Mago, R., and Chu, P. 2003. First report of Wheat streak mosaic virus in Australia. Australas. Plant Pathol. 32:551-553.

9. French, R., and Robertson, N. L. 1994. An RTPCR method for the detection of the wheat streak mosaic virus. J. Virol. Methods 49:93100.

10. French, R., and Stenger, D. C. 2002. Wheat streak mosaic virus. AAB Descriptions of Plant Viruses, No. 293.

11. French, R., and Stenger, D. C. 2003. Evolution of Wheat streak mosaic virus: Dynamics of population growth within plants may explain limited variation. Annu. Rev. Phytopathol. 41:199-214.

12. French, R., and Stenger, D. C. 2005. Population structure within lineages of wheat streak mosaic virus derived from a common founding event exhibits stochastic variation inconsistent with the deterministic quasi-species model. Virology 343:179-189.

13. Gibbs, M. J., Wayper, P., Fourment, M., Wood, J. T., Ohshima, K., Armstrong, J. S., and Gibbs, A. J. 2006. The variable codons of H3 influenza A virus haemagglutinin genes. Arch. Virol. In press.

14. Hall, T. A. 1999. BioEdit: A user-friendly biological sequence alignment editor and analysis program for Windows 95/98/NT. Nucleic Acids. Sympos. Ser. 41:95-98.

15. Hall, J. S., French, R., Morris, T. J., and Stenger, D. C. 2001. Structure and temporal dynamics of populations within wheat streak mosaic virus isolates. J. Virol. 75:1023110243.

16. Halliday, R. B., and Knihinicki, D. K. 2004. The occurrence of Aceria tulipae (Keifer) and Aceria tosichella (Keifer) in Australia (Acari: Eriophyidae). Int. J. Acarol. 30:113-118.

17. Hill, J. H., Martinson, C. A., and Russell, W. A. 1974. Seed transmission of maize dwarf mosaic and wheat streak mosaic viruses in maize and response of inbred lines. Crop Sci. $14: 232-235$.
18. Ho, S. Y. W., Phillips, M. J., Cooper, A., and Drummond, A. J. 2005. Time dependency of molecular rate estimates and systematic overestimation of recent divergence times. Mol Biol. Evol. 22:1561-1568.

19. Jeanmougin, F., Thompson, J. D., Gouy, M., Higgins, D. G., and Gibson, T. J. 1998. Multiple sequence alignment with Clustal $\mathrm{X}$. Trends Biochem. Sci. 23:403-405.

20. Jones, R. A. C., and Burges, N. 2006. Wheat streak mosaic virus: Keeping a new enemy in Check. Aust. Grain 15:4-8.

21. Jones, R. A. C., Coutts, B. A., Mackie, A. E. and Dwyer, G. I. 2005. Seed transmission of Wheat streak mosaic virus shown unequivocally in wheat. Plant Dis. 89:1048-1050.

22. Murray, G. 2006. Update on Wheat streak mosaic virus. Plant Disease Notes. February 2006. NSW Dep. Primary Industries.

23. Saitou, N., and Nei, M. 1987. The neighborjoining method: A new method for reconstructing phylogenetic trees. Mol. Biol. Evol. 4:406 425.

24. Stenger, D. C., Seifers, D. L., and French, R. 2002. Patterns of polymorphism in wheat streak mosaic virus: Sequence space explored by a clade of closely related viral genotypes rivals that between the most divergent strains. Virology 302:58-70.

25. Swofford, D. L. 2002. PAUP*: Phylogenetic analysis using parsimony (*and other methods), version 4. Sinauer Associates, Sunderland, MA.

26. Swofford, D. L., Olsen, G. J., Waddell, P. J., and Hillis, D. M. 1996. Phylogenetic inference. In Molecular Systematics, 2nd ed. D. M. Hillis, C. Moritz, and B. K. Mable, eds. Sinauer Associates, Sunderland, MA.

27. Ward, C. W., Weiller, G. F., Shukla, D. D., and Gibbs, A. J. 1995. Molecular systematics of the Potyviridae, the largest plant virus family. In Molecular Basis of Virus Evolution. A. J. Gibbs, C. H. Calisher, and F. Garcia-Arenal, eds. Cambridge University Press, Cambridge, UK.

Two changes were made in this article on 1 February 2007. On page 168, Table 2, the last heading was changed to "Tamworth 1, SP-5, and SP-1". On page 169, column 3, the sentence starting on line 6 was changed to read "Given the extensive annual movement of breeding material and commercial cultivars of wheat around the continent as seed and the apparent delay in its appearance on the western side of the continent, it is likely that WSMV entered Australia within the last 10 to 20 years." 